\title{
Underwater Duodenal ESD of a Large Adenoma Using the Pocket-Creation Method
}

\author{
João Santos-Antunes ${ }^{\mathrm{a}-\mathrm{c}}$ Rui Morais ${ }^{\mathrm{a}}$ Margarida Marques $^{\mathrm{a}}$ \\ Guilherme Macedo ${ }^{a}$ \\ ${ }^{a}$ Gastroenterology Department, Faculty of Medicine, Centro Hospitalar S. João, Porto, Portugal; bi3S-Instituto de \\ Investigação e Inovação em Saúde, Universidade do Porto, Porto, Portugal; ' IPATIMUP - Institute of Molecular \\ Pathology and Immunology, University of Porto, Porto, Portugal
}

\section{Keywords}

Endoscopic submucosal dissection · Duodenal adenoma · Underwater ESD · Pocket-creation technique - Duodenal ESD

\section{"Underwater ESD" de um adenoma duodenal utilizando o "pocket-creation method"}

\section{Palavras Chave}

Dissecção endoscópica da submucosa · Adenoma duodenal · ESD duodenal · Underwater ESD .

Pocket-creation technique

A 64-year-old woman, without relevant medical history, was referred to our department due to a $5-\mathrm{cm}$ adenoma in the distal part of the second portion of the duodenum (Fig. 1). Due to the instability of the endoscope, the lesion size and localization, a complete resection by piecemeal-EMR was unlikely. Therefore, ESD was offered.

We used hydroxyethylamide with methylene blue for submucosal injection, and dual- and IT-nano knives (Olympus, Tokyo) for submucosal dissection. We started

karger@karger.com www.karger.com/pjg

Karger $\stackrel{\text { ' }}{5}$

BOPEN ACCESS
(C) 2020 Sociedade Portuguesa de Gastrenterologia Published by S. Karger AG, Basel

This article is licensed under the Creative Commons AttributionNonCommercial-NoDerivatives 4.0 International License (CC BYNC-ND) (http://www.karger.com/Services/OpenAccessLicense) Usage and distribution for commercial purposes as well as any distribution of modified material requires written permission. in the oral side by a small incision in the mucosa and then performed underwater ESD using a total of nearly $1 \mathrm{~L}$ of saline, creating a pocket beneath the lesion, with the uneventful en bloc resection of the entire lesion.

One of the major challenges in duodenal ESD is the absence of the contraction of the lesion after mucosal incision, which prevents an easy access to submucosa; at the same time, the muscle layer is very thin and the submucosal injection does not last long. Underwater technique allowed us to have an easier access to the submucosa, by

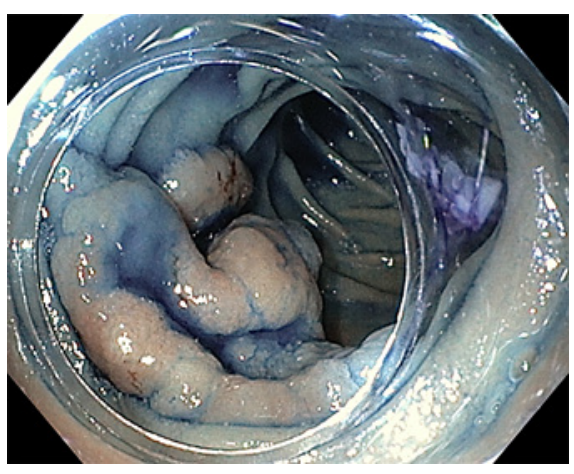

Fig. 1. Duodenal adenoma. 
Fig. 2. Underwater ESD and pocket-creation technique.

Fig. 3. ESD defect; string-clip suturing method; hemospray.
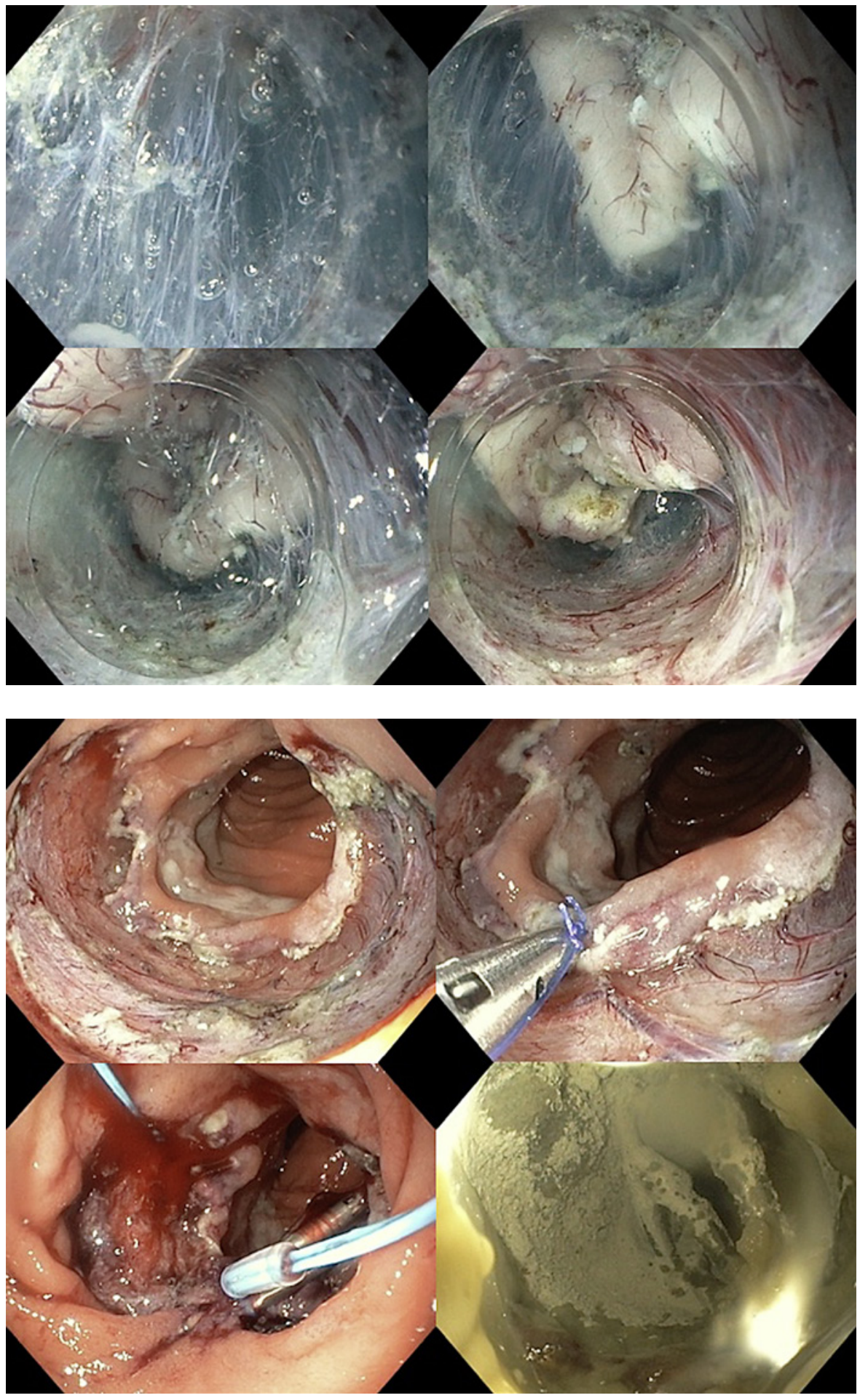

pushing the mucosal flap away from the scope, and providing a clean visualization during the entire procedure. Once in the submucosa, pocket technique [1] allowed us to have a better scope stabilization throughout the proce- dure (Fig. 2); after dissecting the submucosa, we finished by cutting the remaining mucosa circularly.

Besides the high-risk of adverse events during the procedure, duodenal ESD has a high risk of late adverse 
events, due to the exposure of the muscular layer to biliary and pancreatic juices. Therefore, we attempted to close the defect by the string-clip suturing method [2]. First, a clip with a string was passed into the endoscopic channel and displaced in the anal side of the ulcer. Then, a second clip was hooked in the string and displaced in the opposite (oral) side, and the two clips were gathered by pulling the string. After approaching the two margins, we tried to achieve the complete closure. Unfortunately, we were only able to close half of the defect, due to the poor mobility of the duodenum. In order to offer some protection to the muscle layer, we decided to prophylactically apply hemospray in the open area of the ulcer (Fig. 3).

The lesion measured $60 \times 40 \mathrm{~mm}$ and the procedure took $150 \mathrm{~min}$. The patient was admitted to the hospital and stayed there for 1 week to address possible late adverse events related to the inability of complete closure of the defect, with double-dose proton pump inhibitor, that maintained for 8 weeks, and a stepwise progression to a normal diet. No late adverse events were observed.

Histological evaluation showed a high-grade dysplastic lesion, with free margins. Follow-up endoscopy showed a scar with some regenerative tissue; biopsies confirmed the absence of dysplasia.

Duodenal submucosal dissection has, in the West, limited indications due to the high rate of adverse events [3].
No previous Portuguese ESD series included underwater duodenal ESD [4-7]. However, when EMR is not possible, and considering the potentially aggressive surgeries, this can be attempted by experienced endoscopists in ESD.

\section{Statement of Ethics}

The patient gave informed consent for the ESD procedure.

\section{Conflict of Interest Statement}

The authors have no conflicts of interest to declare.

\section{Funding Source}

No funding was received.

\section{Author Contributions}

João Santos-Antunes performed the ESD and wrote the manuscript. Rui Morais, Margarida Marques and Guilherme Macedo provided critical revision of the manuscript.

\section{References}

1 Miura Y, Shinozaki S, Hayashi Y, Sakamoto $\mathrm{H}$, Lefor AK, Yamamoto H. Duodenal endoscopic submucosal dissection is feasible using the pocket-creation method. Endoscopy. 2017 Jan;49(1):8-14.

2 Nishizawa T, Akimoto T, Uraoka T, Mitsunaga Y, Maehata T, Ochiai Y, et al. Endoscopic string clip suturing method: a prospective pilot study (with video). Gastrointest Endosc. 2018 Apr;87(4):1074-8.

3 Pimentel-Nunes P, Dinis-Ribeiro M, Ponchon T, Repici A, Vieth M, De Ceglie A, et al. Endoscopic submucosal dissection: European
Society of Gastrointestinal Endoscopy (ESGE) Guideline. Endoscopy. 2015 Sep; 47(9):829-54.

4 Santos-Antunes J, Baldaque-Silva F, Marques M, Lopes J, Carneiro F, Macedo G. Real-life evaluation of the safety, efficacy and therapeutic outcomes of endoscopic submucosal dissection in a Western tertiary centre. United European Gastroenterol J. 2018 Jun;6(5):7029.

5 Costa RS, Ferreira A, Leal T, Costa D, Rolanda C, Gonçalves R. Endoscopic submucosal dissection for the treatment of superficial epithe- lial gastric neoplasia in a Portuguese Center. GE Port J Gastroenterol. 2019 Mar;26(2):908.

6 Rodrigues J, Carmo J, Carvalho L, Barreiro P, Chagas C. Endoscopic submucosal dissection for gastrointestinal superficial lesions: initial experience in a single Portuguese center. GE Port J Gastroenterol. 2015 Jul;22(5):190-7.

7 Santos-Antunes J, Marques M, Macedo G Endoscopic Submucosal Dissection: experience in Portugal. GE Port J Gastroenterol. 2020 Jan;27(1):71-2. 